\title{
Proceso de producción para la exportación de café de calidad al mercado internacional por parte de la empresa CISA Exportadora en el período 2014-2015
}

\author{
Karen Omara Salinas Artica \\ Noyling Danitza Acuña Hernández ${ }^{3}$ \\ Beverly Castillo Herrera ${ }^{4}$
}

\section{RESUMEN}

El presente estudio analiza el proceso de producción de café de calidad para el diseño de una estrategia que mejore la capacidad de exportación de la empresa CISA Exportadora a mercados internacionales periodo 2014-2015. Esta investigación es de tipo cualitativo se trabajó en la empresa CISA Exportadora, con sede central en Managua y sus cuatro oficinas regionales de Ocotal, Matagalpa, Jinotepe y Jinotega. Se utilizaron entrevistas, guía de observación y una encuesta dirigida a los productores. Una sugerencia es impulsar programas para la integración de nuevos productores y asesorías técnicas para incrementar sus sellos de calidad.

Palabras clave: Producción, exportación, café, mercado internacionales.

Recibido: 10 de diciembre de 2015

Aceptado: 12 de enero de 2016

1 Este artículo se basa en la investigación titulada Proceso de producción y exportación de café de calidad al mercado internacional por parte de CISA Exportadora en el periodo 2014.2015. Para optar al título de Licenciatura en Administración de Empresa por la UNAN-Managua, FAREN-Estelí.

2 UNAN-Managua, FAREM-Estelí. Correo electrónico: omarasalinas17@gmail.com

3 UNAN-Managua, FAREM-Estelí. Correo electrónico: noyling3811@gmail.com

4 Master en Ciencias Sociales por la Universidad de Guadalajara, estudiante del Doctorado en Ciencias Sociales de la Universidad del Zulia, Venezuela. Docente titular de la UNAN-Managua, FAREM-Estelí. Correo electrónico: beverly. castillo@yahoo.com 


\section{Production process for exporting quality coffee to the international market by the Exporting Company CISA in the period of 2014-2015}

\section{SUMARY}

This study analyzes the process of production of quality coffee to design a strategy to improve the exporting capacity of the exporting company to international markets during 2014-2015. This is a qualitative research, it was carried at CISA Exporting Company, in Managua and its four regional offices Ocotal, Matagalpa, Jinotepe and Jinotega. Interviews, observation guide and surveys to the producers were used. One suggestion is to promote programs to integrate new producers and technical advices to increase the quality levels.

Keywords: production, export, coffee, international market 


\section{INTRODUCCIÓN}

La presente investigación analiza el proceso de producción de café de los productores que abastecen CISA Exportadora y propone una estrategia que mejore la capacidad de exportación de café de la empresa a mercados internacional. Este estudio ayuda a la empresa a hacer una autoevaluación de sus procesos que conlleve a la retroalimentación eficaz, para que mejoren su capacidad exportadora y servirá a los nuevos productores como fuente de información para conocer sus procesos de producción y el acceso a sellos de calidad para exportar mercados internacionales.

CISA Exportadora es la empresa exportadora de café más grande del país. Inicio operaciones en 1952 y hoy tienen más del 35\% de participación en el mercado nacional. Posee cuatro oficinas comerciales en Jinotega, Matagalpa, Jinotepe y Ocotal; seis agencias de compra, tres beneficios de café y más de cien puntos de compra que se activan durante la temporada de cosecha desde noviembre enero del siguiente año. Así mismo, tienen una activa participación en mercados diferenciados.

Sin embargo para el periodo 2014-2015 CISA Exportadora paso de ser la principal exportadora de café a posicionarse en el segundo lugar a causa de las plantaciones agotados, la sequía y a la competencia por parte de la empresa Alba Alimentos de Nicaragua (ALBALINISA). Las plantaciones agotadas afectadas por las variaciones en el clima, por tercer ciclo consecutivo, repercutieron en una baja en la producción de café en el departamento de Matagalpa, donde la cosecha del ciclo 2014-2015 en el mes de febrero solo llevaba el $70 \%$ de su recolección.

Cuando se habla de proceso de producción de café nos referimos a las etapas que se realizan desde la recolección del fruto hasta el secado del grano, las cuales son siembra del café, recolección del fruto, despulpado del fruto, fermentación, lavado y secado. (Asociación nacional de cafe., 2013)
La exportación de café es toda salida del territorio aduanero del país, de café en oro o cualquier estado más avanzado de procesamiento en que se encuentre, cuya clase, tipo, calidad y peso de embarque corresponden al declarado en el contrato respectivo y amparado en los formatos respectivos de exportación. (Ley del cafe, 2001)

\section{MATERIAL Y MÉTODOS}

En la primera etapa de la investigación se recopilo información secundaria sobre el tema, para diseñar el protocolo de la investigación. Se consultaron libros de administración de empresa y folletos sobre el proceso de producción de café de la biblioteca Urania Zelaya de la FAREM Estelí. Además se consultaron libros en línea y páginas web para dar veracidad a la información.

En el trabajo de campo se aplicaron fuentes primarias de carácter cualitativo como la entrevista y la guía de observación, las que ayudaron a profundizar sobre el estudio de caso de la empresa CISA Exportadora. Se aplicaron, 5 entrevistas a productores, una entrevista dirigida al gerente general de la empresa Ing. Luis Alberto Chamorro y otra al Ing. Oscar Cuevas Gerente de Producción. También se aplicaron 322 encuestas, productores que reciben beneficios de: financiamiento y asistencia técnica. Las encuestas fueron dirigidas a los productores de las zonas donde se encuentran las oficinas comerciales (Matagalpa, Jinotega, Jinotepe y Ocotal). La guía de observación se aplicó para verificar el proceso de producción de café que efectúan los productores en sus fincas.

\section{RESULTADOS}

Los orígenes de CISA Exportadora en Nicaragua datan del Siglo XIX, en el seno de la familia del caficultor Enrique Baltodano, quien se convirtió en el principal caficultor del Pacífico del país. Su hijo Moisés Baltodano tomo la iniciática que sus amigos 
productores le dieran el café en consignación para exportarlo en Londres.

Duilo Baltodano funda CISA Exportadora 1952 gracias a la tradición heredada de su papa Moises Baltodano que tenía relaciones con compradores de Europa y Estados Unidos y los vendedores de café establecidos en Nicaragua. Se abrieron oficinas en el contiguo al almacén deportivo que estaba en la vieja Managua, con el señor Hernaldo fue parte de esta gran empresa por su gran aporte.

En los años 80 CISA cierra operaciones y los integrantes de la familia Baltonado abandonan el país. José Antonio Baltonado radicó en Estados Unidos y funda MERCON CORPORATION en 1982 como una empresa exportadora que a su vez abre empresas de exportación en muchas partes del mundo.

En 1990 reabren CISA Exportadora en Nicaragua, con la meta de ser la mejor empresa de exportación de café del país. La principal Misión de CISA Exportadora es convertirse en un proveedor de café líder e integrado que brinde la mejor experiencia al cliente.

Su misión como empresa es brindar la mejor experiencia de servicio a nuestros clientes a través del desarrollo de relaciones directas, con enfoque basado en tres pilares fundamentales: Mejora continua, Sostenibilidad del negocio apoyando a los productores para aumentar su productividad promoviendo buenas prácticas ambientales y mejorando la calidad de la Educación y Salud en las comunidades cafetaleras donde operan, y Desarrollo de sus colaboradores trabajando de manera constante para brindarles condiciones laborales idóneas y oportunidades en donde puedan crecer y alcanzar su máximo potencial.

En CISA Exportara se trabaja con una visión de un solo grupo y un solo equipo. Esto significa que todos los colaboradores, están integrados bajo una misma cultura, compartiendo buenas prácticas y aprenden juntos para seguir creciendo. Los valores que sustenta la empresa son: integridad, excelencia, trabajo en equipo y espíritu emprendedor.

\section{Estructura orgánica de CISA Exportadora.}

CISA Exportadora, S.A. es parte de MERCON Coffee Group, quien tiene presencia en diferentes ciudades como: Miami, Barcelona y la ciudad de Ho Chi Minh, desde donde se dirigen las operaciones comerciales para ofrecer el café a los tostadores más importantes del mundo.

La estructura organizativa de CISA Exportadora presenta como nivel más alto la Dirección General apoyado por de tres directores de staff. El Director General delega en siete departamentos encargados de llevar las operaciones de la empresa: Gerente de Recursos Humanos, Gerente de Finca, Vice Gerencia, Gerente Comercial del país, Gerente comercial de Centroamérica, analista comercial, Gerencia de proyectos. 


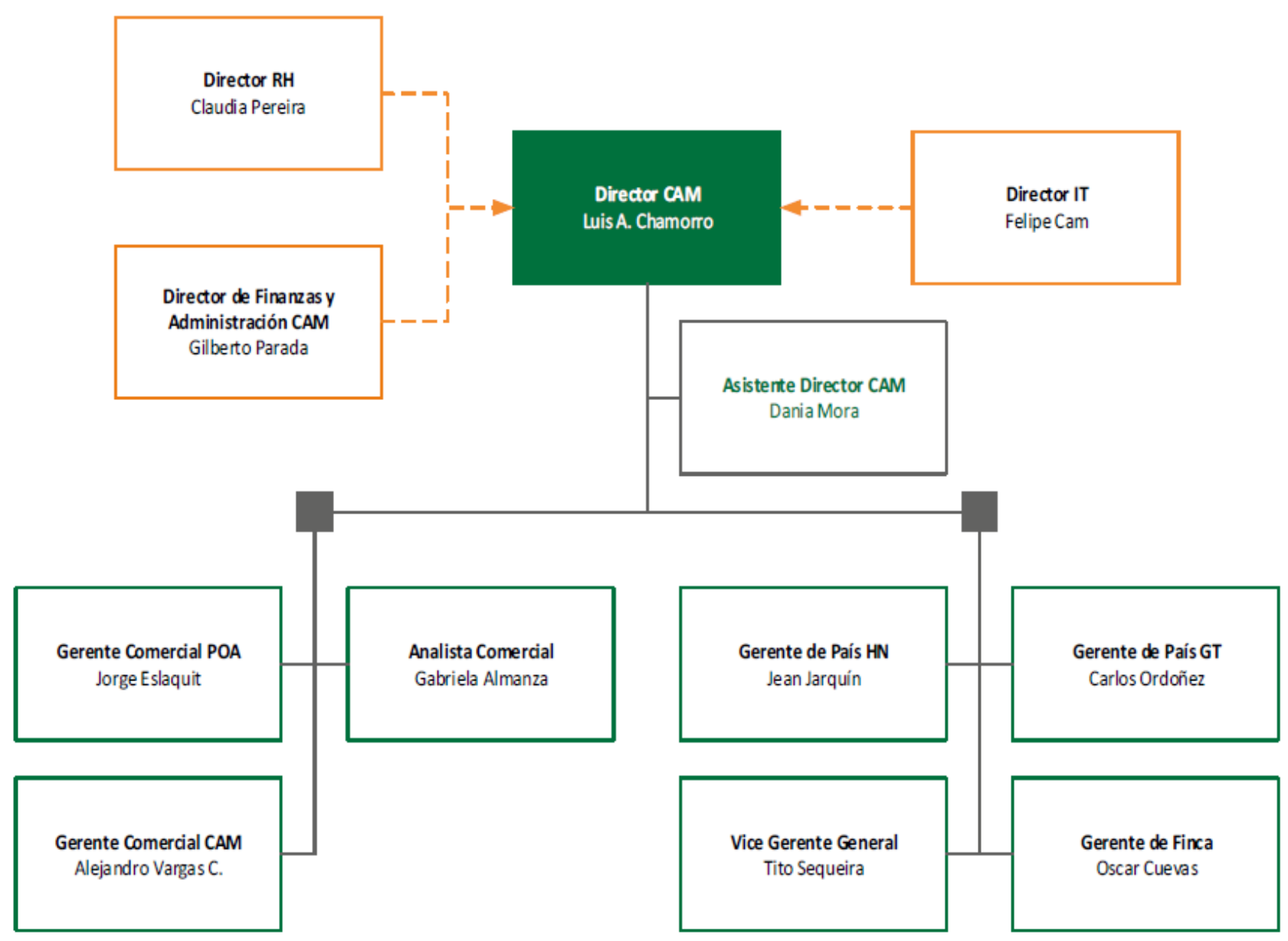

Fuentes: Datos secundarios, información documental, CISA Exportadora.

Asu vez en cada sucursal de Ocotal, Jinotega, Matagalpa y Jinotepe se realizan las gestiones de compras, tienen un beneficio seco ubicado en Matagalpa y es dirigida desde la sede central ubicado en Managua.

La empresa reconoce que sus colaboradores son un pilar fundamental para el éxito del Grupo. Por ello, se garantizan prácticas de empleo justas, todos los trabajadores son tratados por igual y con respeto, sin importar edad, sexo, raza, religión, discapacidad física, o cualquier otro factor prohibido por ley. En el 2015 la empresa cuenta con 163 empleados permanentes y 2,500 temporales para periodos de la cosecha cafetalera.

\section{Estrategias de atención a los productores}

\section{Financiamiento}

CISA Exportadora, recibe préstamo por US\$10 millones de dolores que le permite financiar a miles de productores para mejorar sus cafetales y ampliar su producción. Esta estrategia permite a la empresa expandir su volumen de negocio y , al contar con café de mejor calidad listo para la exportación.

Las tasas de interés del crédito a los productores, oscilan entre $9 \%$ y $12 \%$ anual, dependiendo del cliente y a 7 años plazo. El financiamiento es proporcionado a los productores cuyo historial de muestra que su producción es vendida consecutivamente a CISA Exportadora y quienes utilizan el financiamiento para la mejora e inversión de sus fincas cafetaleras. 
Otro tipo de financiamiento extraordinario se brinda al productor cuando presente alguna dificultad en sus fincas o alguna necesidad familiar, Este tipo de préstamo se les aplica una tasa de interés del 15\% anual.

El financiamiento facilitado por CISA Exportadora presenta una serie de ventajas y desventajas en comparación con las otras empresas comercializadoras y exportadoras de café, van en función al financiamiento y las tasas de interés que se aplican, estas desventajas afectan directamente al productor y a la empresa le porque permite que la competencia capte más clientes.

\section{Ventajas del financiamiento}

- Restructuración de financiamiento a mediano plazo: cuando que el productor no cumple con el pago del crédito estipulado en el contrato, se le restructura la deuda cuando sea por motivos de fuerza mayor como: catástrofe, plagas.

- No se cobra intereses moratorios: En comparación con las financieras, cuando el productor se retrasa con el pago del préstamo, no se aplican intereses moratorios.

- Financiamiento ágil y rápido: No requiere de tantos documentos para aprobar un crédito, luego de cumplir con el requisito de la asistencia técnica, el crédito es entregado rápidamente.

\section{Desventajas del financiamiento}

- La tasa de interés es elevada en comparación con otras exportadoras de café: En exportadoras como ATLANTIC las tasas de interés oscilan entre 11\% y $12 \%$, mientras que la empresa CISA aplica la tasa del $15 \%$ más una comisión del $2 \%$ anual, en algunos casos hasta el 20\% de interés anual.

- Si el cliente queda mal con un financiamiento se cortan relaciones futuras como la fijación de precios.

- La competencia como Exportadora ATLANTIC al brindar un financiamiento da un periodo de gracia de 3 años, durante ese periodo no cobra intereses sino a partir del 4 año, siendo un crédito a largo plazo.

\section{Asistencia técnica}

CISA Exportadora incorporó desde la cosecha 20062007 un programa de asistencia técnica y atiende a los productores cuatro veces en el ciclo de cosecha. Para algunos productores existe una asistencia personalidad que comprende una visita cada mensual. Cada una de las visitas que recibe el productor es para la indicación adecuada del manejo y buenas prácticas en las fincas.

\section{Certificaciones (sellos de certificación)}

CISA Exportadora, S.A. forma parte de programas de certificación, globales y sectoriales que contribuyen con la promoción de la responsabilidad social y el desarrollo de prácticas productivas respetuosas del medio ambiente y las comunidades en las que la empresa tiene incidencia. Se cuenta con certificaciones de: Rainforest Alliance, AAA Sustainable Quality Ecollaboration de Nespresso, UTZ Certified, Código de Conducta 4C y el Programa C.A.F.E. Practices de Strabucks, que respaldan las buenas prácticas sociales y ambientales.

Todos estos certificadores de clase mundial, dan garantías que el café se cultive y procese de manera sostenible, con altos estándares de calidad y siguiendo las mejores prácticas agrícolas. De esta manera los agricultores sus familias y comunidades reciban una mejor retribución por su cosecha en los mercados internacionales.

\section{Responsabilidad social empresarial.(RSE)}

Desde 1996 CISA Exportadora ha concentrado sus esfuerzos en desarrollar un proyecto integral para mejorar el nivel de vida de las comunidades cafetaleras de Nicaragua. La implementación de este modelo ha tenido un impacto profundo en las comunidades 
rurales y ha sido posible por las alianzas con clientes tostadores, instituciones financieras, ministerios $\mathrm{y}$ Organismos No gubernamentales.

CISA Exportadora cuenta con dos programas de responsabilidad social: semillas digitales y semillas saludables. Semillas Digitales es su programa emblemático, está orientado a mejorar la calidad de la educación primaria en las zonas donde operan, desarrollado en coordinación con el Ministerio de Educación de Nicaragua (MINED), la Universidad de Pensilvania, empresas hermanas del grupo y otros socios de la industria relacionados con la actividad cafetalera.

Semillas Digitales es un programa que fortalece las capacidades y conocimientos de profesores $\mathrm{y}$ alumnos integrando la tecnología a través de una sólida metodología desarrollada con la Universidad de Pensilvania; que hace énfasis en el fortalecimiento de las habilidades de lectura escritura y matemáticas.

Este modelo también promueve la inversión en infraestructura escolar y el involucramiento de padres de familia y de la comunidad.

Semilla saludable está comprometida con la salud de las comunidades donde trabajan través del apoyo a brigadas médicas que apoyan en Nicaragua. La labor incluye identificar y brindar apoyo logístico a los pacientes y sus familias durante el tratamiento médico. Actualmente, apoya a Operación Sonrisa Nicaragua en: campañas de recaudación de fondos con colaboradores, clientes y amigos, Identificación de casos en las comunidades cafetaleras, donación de equipo médico.

\section{Valoración de los productores sobre las estrategias de CISA Exportadora}

Se aplicó una encuesta a productores para conocer sobre los beneficios que le ofrece la empresa CISA
Exportadora, el 92\% de los productores respondieron que reciben financiamiento de la empresa. Y 91\% que respondieron la fijación de precios a futuro.

Cuadro No 1 Beneficios que ofrece CISA Exportadora

Universo 322

\begin{tabular}{lll}
\hline Tipos de beneficios & Frecuencia & \% \\
\hline Financiamiento & 296 & 92 \\
Asistencia Técnica & 288 & 89 \\
Certificación de café & 186 & 58 \\
Mejor precio de compra & 109 & 34 \\
Otros (fijación de precios) & 292 & 91 \\
\hline
\end{tabular}

\section{Fuentes: Datos primarios Agosto 2015}

"Uno de los beneficios más importantes, que no lo ofrece ninguna otra empresa es poder fijar precios a futuro, eso brinda seguridad porque aunque el precio del café bajé en el periodo fijado, ellos me pagarían al precio ya acordado. Y si el precio sube no pierdo porque se cuáles son los costos en los que incurro para poder producir un quintal de café" (W, Tórrez, junio 2015).

La tasa de interés cobrada por CISA Exportadora es variada, El $35 \%$ de los productores afirman pagar una tasa de interés del $15 \%$ anual y un $8 \%$ paga una tasa de interés del $20 \%$ anual (ver cuadro N0 2). CISA exportadora tiene dos tipos de financiamientos, una se otorga después de terminar el ciclo anterior e inicio, un nuevo periodo productivo, y otro financiamiento es otorgado en cualquier momento del ciclo y el interés es mayor a $15 \%$.

Cuadro N0 2 Tasa de interés

\begin{tabular}{lll}
\hline \multicolumn{3}{c}{ Universo 296 } \\
\hline Tasa de interés & Frecuencia & \% \\
\hline 12 & 48 & 16 \\
14 & 51 & 17 \\
15 & 104 & 35 \\
16 & 30 & 10 \\
18 & 25 & 8 \\
20 & 38 & 13 \\
Total & 296 & 100 \\
\hline
\end{tabular}

Fuentes: Datos primarios Agosto 2015 
El $58 \%$ de los productores valoran financiamiento brindado por la empresa bueno; sin embargo un $1 \%$ lo consideraron malo. Aunque el interés de CISA Exportadora sea más alto que de una institución financiera los productores consideran bueno el financiamiento porque no tienen que realizar mucho papeleo, tienen prórroga cuando que tienen algún inconveniente para realizar los pagos.

E1 30.90\% productores encuestados afirman recibir tres visitas de asistencia técnica en el año por parte del personal técnico de CISA Exportadora. La valoración que sobre la asistencia técnica que les brinda el 51\% consideran como regular, mientras otro $30 \%$ la valora como buena.

"Son asistencias muy tardadas, una es practicada cuando van a dar el financiamiento para valorar el monto y la otra a finales de cosecha de café, además que algunas veces no asesoran bien” (Y, Ortez, junio 2015).

Con respecto a los programas de Responsabilidad Social Empresarial (RSE) que impulsa la empresa, el $73.29 \%$ afirman no ser beneficiados y un $26.71 \%$ son beneficiados.

\section{Requisitos para la exportación}

Cuando CISA Exportadora recibe la solicitud del cliente sobre la cantidad de café, se ejecuta un plan acopio de acuerdo a la venta solicitada, y se elabora la Dirección comercial y se envía al beneficio seco con anticipación.

Para celebrar un contrato de compra-venta se requiere del envió de una muestra de café al comprador para verificar la calidad, y se toma una muestra representativa del lote que esta puede tener un peso de dos a cinco kilos.

La I fase del proceso de exportación incluye: La Declaración de Mercancías de Exportación, factura proforma, instrucción de embarque, certificado de calidad emitido por el Organismo Nacional de Certificación de la Calidad del Café

La II fase de la exportaciones incluye el tramitar con la línea naviera Bill of Lading, Certificado de Origen SGP, para exportar a Europa, Factura definitiva.

Cuadro No 3. Producción comprada a productores. Octubre 2014-Septiembre 2015

\begin{tabular}{lrccc}
\hline Empresa exportadora & Kilogramos & Sacos 69 Kgs & Sacos 60Kgs & Quintales \\
\hline CISA Exportadora & $41,370,557.99$ & $599,573.31$ & $689,509.54$ & $899,359.96$ \\
\hline
\end{tabular}

Fuente: Datos secundarios, información documental CISA Exportadora. 2015

Cuadro No 4. Exportaciones de Octubre 2014 a Septiembre 2015

\begin{tabular}{lcccc}
\hline Empresa exportadora & Kilogramos & Sacos de 69 Kgs & Sacaos de 60 Kgs & Quintales \\
\hline CISA Exportadora. & $33,910,293.44$ & $491,453.5296$ & $565,171.75$ & $737,180.291$ \\
\hline
\end{tabular}

Fuente: Datos secundarios, información documental, CISA Exportadora, 2015 
De toda la producción comprada hasta el mes de julio del 2015 Comercial internacional exportadora solo el $80 \%$ fue dirigido para la exportación, mientras que el $20 \%$ fue utilizado para la venta local.

CISA Exportadora dirige sus exportaciones principalmente al mercado Estados Unidos, España, Londres, Francia, Inglaterra, Suecia, Australia, Finlandia, Marruecos, Arabia Saudita, Korea del Sur, Egipto, Japón, Hong Kong.

CISA Exportadora compra a los productores el café para exportarlo pero no toda la compra es utilizada para la exportación. El 56\% de los productores encuestados incidan que de un 71 a $80 \%$ de su producción de café utilizado para la exportado.

"El porcentaje restante de la producción total es vendida en a los tostadores naciones de Nicaragua" (L. Chamarro. 2019 mayo 29).

Precio de compra

CISA Exportadora utiliza dos formas de adquirir el café, el primero por la fijación de precio a futuros con los productores que están en la línea de proveedores fijos, quienes reciben financiamiento y firman contratos de compra-venta de café con la empresa, estos productores son serios, responsables y que tengan un historial de entrega de café periódicamente a la empresa.

La fijación precio la realiza una parte de la producción total de café, la valora $r$ un técnico de CISA Exportadora y la otra parte se paga según el precio del mercado local.

De los 2000 productores que trabajan con CISA Exportadora solo 1330 decidieron fijar precios, lo que representa el $66.50 \%$ de los productores.
Cuadro No 5. Precio de compra de café a productores y productoras

\begin{tabular}{llll}
\hline No. Productores & Precio & Años & \% \\
\hline 520 & $\$ 175$ & 5 & 39 \\
350 & $\$ 160$ & 4 & 26 \\
290 & $\$ 190$ & 4 & 22 \\
170 & $\$ 200$ & 3 & 13 \\
TOTAL: 1330 & & & 100 \\
\hline
\end{tabular}

Fuente: Datos secundarios, información documental CISA Exportadora. 2015

Otra manera de cumplir con la demanda del mercado internacional es comprando a productores que venden su café ocasionalmente a la empresa. El precio de compra para estos productores es el que está en el mercado.

Durante los primeros siete meses de la cosecha 2014-2015 el precio del quintal de café alcanzó un promedio de $\$ 178.8$. En el 2015 el precio se cotiza de $\$ 117.18$ a $\$ 130.00$ según la bolsa de valores de New York. Los precios disminuyen por los competidores internacionales como: Vietnam, Brasil y Colombia.

\section{Criterios de calidad en la producción del café}

"CISA Exportador dirige su producto a dos mercados, selectivos y consumo general. Para que un café sea aceptado en un mercado diferenciado debe cumplir con los criterios de calidad: Variedad de café, Altura, Prácticas de las fincas con respecto al café, café de sombra, el corte del café y el beneficio húmedo." (O, Cuevas. 2015, mayo 29)

Para CISA Exportadora, los café de mejor calidad en cuanto a variedad es el café robusto y el arábico. El café robusto se trata de un árbol o arbusto liso de hasta 10 metros de altura con un sistema radicular somero, con hojas anchas que a veces adquieren una apariencia corrugada $\mathrm{u}$ ondulante, oblonga - elíptica, cortas, acuminadas, redondeadas o ampliamente acuñadas en su base, de 15-30 cm de largo y 5-15 cm de ancho; la nervadura media es plana por arriba, prominente por 
debajo, las nervaduras laterales son de 8-13 pares; el peciolo es fuerte de $8-20 \mathrm{~mm}$ de largo; las estípulas interpeciolares son ampliamente triangulares, largas puntiagudas, connatas en su base, semipersistentes.

Tiene flores blancas, algunas veces ligeramente difusas con rosa, en dos racimos axilares, sésiles, con o sin brácteas con hojas. La corola de 5-7 lóbulos, el tubo sólo un poco más corto que los lóbulos. Los estambres y el estilo bien salidos. Florece irregularmente tomándole hasta 11 meses para cuajar todas las flores.

Las bayas ampliamente elipsoides, más o menos de 8-16 mm, estriadas cuando secas. La planta es muy variable en su estado silvestre. La planta robusta tiene mayor rendimiento que café arábica y es menos susceptible a plagas y enfermedades, pero con sabor más amargo que aquella.

Mientras que el café arábica se trata de un arbusto o árbol pequeño liso, de hojas lustrosas. Las hojas son relativamente pequeñas, pero varían en anchura, promediando de 12-15 cm de largo y más o menos $6 \mathrm{~cm}$ de ancho, de forma oval o elíptica, acuminadas, cortas, agudas en la base, algunas veces un tanto onduladas, siemprevivas.

\section{Buenas prácticas en las fincas}

Las buenas prácticas en las fincas que CISA Exportadora considera importantes para la calidad y rendimiento del café son:

1. Que las plantaciones sean con sombras.

2. Alturas igual o menos a $950 \mathrm{msnm}$ para las variedades comunes de café y alturas superiores a $950 \mathrm{msnm}$ para variedades resistentes a ojo de gallo.

3. Utilización de productos no tóxicos para evitar el deterioro de las plantas.

4. Para cortar el café se debe asegurar que esté completamente maduro, en algunos casos cuando las condiciones de clima lluvioso pueden exigir el corte de café pinto para evitar la caída de los frutos.
5. La sobre maduración de café produce problemas de calidad y para minimizar su ocurrencia el intercalo de tiempo entre pasadas de corte en cada plantío debe ser de 15 a 20 días promedio.

6. Se debe evitar el corte de café verde, y por eso es necesario supervisar a los cortadores.

7. El corte debe ser grano por grano para asegurar el rendimiento y la calidad del café.

8. El traslado del café al beneficio húmedo debe ser inmediatamente después de la medida en el campo para evitar deterioro o inicio de la fermentación del fruto.

9. El buen beneficiado húmedo inicia con un equipo de despulpado limpio y bien calibrado para evitar contaminación y se dañe la calidad y daños por mordedura o quebradura de grano.

10. El lavado del café para quitar el mucilago debe realizarse con agua limpia.

11. Orear el café en cajillas de madera y cedazo para reducir los riesgos de fermentación adicional o presencia de moho.

12. El transporte del café lavado al beneficio seco debe ocurrir a lo inmediato.

\section{Cumplimientos de los sellos de calidad por parte de los productores.}

Los productores deben cumplir con ciertos criterios en sus fincas para garantizar los sellos de calidad y que sea considerado para la exportación.

1. Sistema de gestión social ambiental.

2. Conservación de ecosistema.

3. Protección de la vida silvestre.

4. Conservación de los recursos hídricos.

5. Trato justo y buenas condiciones a los trabadores.

6. Salud y seguridad a los trabajadores.

7. Manejo integrado de los cultivos.

8. Manejo integrado de los suelos.

9. Manejo integrado de los desecho.

Para asegurar del cumplimiento de estos criterios, los productores son visitados por los técnicos encargados por cada sello de calidad. 


\section{FODA de CISA Exportadora}

Mediante el análisis de los resultados obtenidos en la investigación se identificaron las principales Fortalezas, Oportunidades, Debilidades y Amenazas de CISA Exportadora, a través de este análisis permitió proponer estrategias para mejorar la capacidad exportadora de la empresa al mercado internacional.

\section{FORTALEZAS}

- Sucursales en todas las regiones productoras de café.

- Tradición de exportación por generaciones en el ámbito cafetalero

- Certificada con Normas ISO 9000 - 2008

- Política de crédito a los colaboradores y convenios interinstitucionales.

- Buenas relaciones con Transnacionales y cooperación internacional.

- Empresa líder en RSE. (Responsabilidad Social Empresarial)

\section{OPORTUNIADES}

- Ampliación de la cartera de productos a exportar. (Café robusta, $\mathrm{CO} 2$.).

- Ampliación en el número de clientes atendidos, así como de las zonas a atender.

- Certificarse con más sellos de calidad.

- Integrarse dentro de las cadenas de valor de cada rubro de exportación.

- Orientarse a la investigación y desarrollo.

\section{DEBILIDADES}

- Regular atención al cliente

- Asistencia técnica esporádica.

- Poco interés en el desarrollo de los distintos eslabones de cadenas de valor en la exportación de café.

- Inexistencia de una relación permanente con los productores.

- Interés crediticio alto.

Después de haber establecido el análisis FODA, las estrategias que se proponen son en base a sus debilidades para mejor la capacidad exportadora.

- Línea No 1: Aprovechamiento de las sucursales en las regiones cafetaleras para la captación de nuevos productores.

- Línea No 2: Mejorar la relación con los productores para garantizar la cartera de clientes.

- Línea No 3: Mejorar los distintos eslabones de la cadena de valor mediante una mejor integración de la misma.

- Línea No 4: Flexibilización en las políticas de crédito a los productores.

- Línea No 5: Incremento de café certificado por los sellos de calidad.

\section{CONCLUSIONES}

Esta empresa cuenta con beneficios para los productores como: financiamiento, asistencia técnica, certificación y responsabilidad social. Un $92 \%$ de los productores reciben financiamiento, mientras que un $22 \%$ recibe asistencia técnica personalizada que va de 8 a 12 visitas en el año y un $89 \%$ recibe asistencia de 3 visitas en el año, el cual los productores no la consideran como una asistencia técnica. y solo $58 \%$ cuenta con programas de certificación de café.

Para que CISA Exportadora pueda exportar su café al mercado internacional, debe cumplir con los requisitos que exige de cada uno de los tostadores le exige, así mismo debe realizar los procesos de exportación del país de exportador y del importador los cuales son: declaración de mercancía, factura proforma, instrucciones de embarque, certificado fitosanitario de 
Organismo Internacional de café (OIC), los tramites de la línea naviera, certificado de origen y la factura definitiva.

La calidad del café va depender muchas veces de la variedad de la planta, la altura de donde estén ubicados los cafetales, grado de humedad Prácticas de las fincas con respecto al café, café de sombra, el corte del café y el beneficio húmedo.

En el trascurso de octubre 2014 a septiembre del 2015 CISA Exportadora exporto 33,910,293.44 kilogramos, es decir 737,180.291 quintales de café a un precio promedio de U\$ 180. 47.

\section{BIBLIOGRAFÍA}

Asociación Nacional de café. (2013). Proceso del cultivo. Dirección Electrónica http://www. asoexport.org/ Consultada: 18/04/2015.

Ley N0 368, Diario Oficial La Gaceta, Nicaragua. 24 de Enero del 2001. 